Onggo, T.M. · Sumadi · R. Fauziah

\title{
Pertumbuhan, hasil dan kualitas tomat cv. Marta-9 pada berbagai sistem budidaya dalam rumah plastik di dataran medium Jatinangor
}

\section{Growth, yield and quality of marta-9 tomato cultivars under various culture system planted in plastic house in medium elevation of Jatinangor.}

Diterima : Januari 2015/Disetujui : Februari 2015/Dipublikasikan : Maret 2015

CDepartment of Crop Science, Padjadjaran University

\begin{abstract}
Planting tomato using hydroponic system, yielded higher quantity and quality of tomato fruit and could be continuously, but the system need a higher cost for plant nutrient, therefore an alternative culture system that could match yield and quality with less cost than hydroponic system needed to evaluate. The aim of this experiment was to study the different culture systems of tomato planted in plastic house that applicable in medium elevation, with lower cost, and to observed the effect of productive stems number on growth, yield and quality of tomato. The experiment was conducted from June up to October 2013 in plastic house of Protected Culture Laboratory of Agriculture Faculty, University of Padjadjaran, located at about 730 meters above sea level. The experimental design used was a Randomize Block Designed (RBD) in factorial pattern, consisted of two factors and four replications. The first factor was culture system consisted of three levels (hydroponic, semi hydroponic and non hydroponic) and the second factor was number of stems, consisted of two levels (single stem and double stems). The results showed that there ware no interaction effects between culture system and number of stems on growth, yield and quality of Marta-9 tomato cultivar. Semi hydroponic and non hydroponic system in this experiment resulted lower plant, thinner stem diameter,smaller leafs compared to hydroponic system. The high number of blossom end rot in semi hydroponic and non hydroponic system affected yield i.e. less fruits number and fruit
\end{abstract}

\footnotetext{
Dikomunikasikan oleh Jajang Sauman Hamdani

Onggo, T.M. ${ }^{1} \cdot$ Sumadi $^{1}$ · R. Fauziah ${ }^{2}$

1 Staf Fakultas Pertanian Universitas Padjadjaran

2 Alumni Fakultas Pertanian Universitas Padjadjaran
}

weight per plant, and less percentage of A quality. Plant with single stem grown higher and bigger leaf size compared to the double stems, however produced the same percentage of marketable fruits, and same percentage of weight and number of A fruit quality.

Keywords : Hydroponic - Non hydroponic . Semi hydroponic - Number of productive stems . Marta-9 tomato cultivar

Sari Penanaman tomat dalam rumah plastik dengan sistem budidaya hidroponik, mengOhasilkan buah dengan kuantitas dan kualitas baik serta dapat dilakukan secara kontinu, namun kekurangan sistem tersebut adalah bahan kimia yang digunakan untuk hara tanaman mahal, sehingga perlu dicarikan sistem budidaya alternatif yang dapat mengimbangi hasil dan kualitas hasil sistem hidroponik. Tujuan dilaku-kannya penelitian ini adalah untuk mempelajari berbagai sistem budidaya tanaman tomat dalam rumah plastik yang dapat diaplikasikan di dataran medium dengan biaya yang lebih murah serta menguji jumlah batang produksi yang dapat menghasilkan pertumbuhan dan hasil tanaman serta kualitas tomat yang baik. Penelitian dilakukan dari bulan Juni sampai dengan Oktober 2013 di rumah plastik Laboratorium Kultur Terkendali Fakultas Pertanian Universitas Padjadjaran, dengan ketinggian tempat $730 \mathrm{~m}$ di atas permukaan laut.Percobaan dilakukan dengan Rancangan Acak Kelompok (RAK) pola faktorial yang terdiri dari dua faktor dan empat ulangan. Faktor pertama adalah sistem budidaya yang terdiri dari tiga taraf (hidroponik, semi hidroponik dan non hidroponik) dan faktor kedua adalah jumlah batang produksi yang terdiri dari dua taraf (batang tunggal dan batang ganda). Hasil penelitian menunjukkan bahwa tidak terjadi

Onggo, dkk. : Pertumbuhan, hasil dan kualitas tomat cv. Marta-9 pada berbagai sistem budidaya dalam rumah plastik di dataran medium Jatinangor 
pengaruh interaksi antara sistem budidaya dan jumlah batang produksi terhadap pertumbuhan, hasil dan kualitas hasil tomat cv. Marta-9. Sistem budidaya semi hidroponik dan non hidroponik menghasilkan pertumbuhan tanaman yang lebih rendah dicirikan dengan tinggi tanaman, diameter batang,serta ukuran daun yang lebih rendah dibanding sistem budidaya hidroponik. Tingginya jumlah buah yang terkena blossom end rot pada sistem budidaya semi dan non hidroponik berimbas pada jumlah buah dan bobot buah per tanaman yang lebih rendah serta persentase bobot buah kualitas A yang lebih rendah dibandingkan sistem budidaya hidroponik. Perlakuan batang tunggal menghasilkan tanaman dengan tinggi tanaman serta ukuran daun yang lebih besar dibanding penggunaan batang produksi ganda, namun baik perlakuan batang tunggal atau ganda menghasilkan persentase jumlah dan bobot buah layak pasar serta persentase bobot dan jumlah buah kualitas A yang sama.

Kata kunci : Hidroponik - Non hidroponik . Semi hidroponik - Jumlah batang produksi . Tomat kultivar Marta-9

\section{Pendahuluan}

Penanaman tomat dalam rumah plastik merupakan salah satu teknik budidaya untuk mendapatkan kualitas buah tomat yang baik (Kanyomeka and Shivute, 2005). Di Indonesia teknik budidaya tersebut umumnya dilakukan pada penanaman tomat 'beef' yang ukuran buahnya besar,ditanam dengan sistem hidroponik dan menggunakan media bukan tanah karena tomat jenis ini peka terhadap berbagai penyakit tular tanah. Media yang dipilih antara lain arang sekam karena mempunyai sifat porus, tidak mudah lapuk, dapat mengikat air dan larutan hara, steril, bersih, mudah didapat dan harganya relatif murah. Pada sistem budidaya hidroponik, nutrisi yang diperlukan tanaman dipasok bersamaan dengan pengairan. Komposisi unsur hara dalam larutan nutrisi dan dosis dalam aplikasinya disesuaikan dengan umur dan kondisi tanaman.Bahan kimia untuk meramu nutrisi tersebut cukup mahal, sehingga budidaya dengan sistem hidroponik memerlukan biaya yang besar dan hanya digunakan untuk komoditas dengan nilai ekonomi tinggi.

Tomat kultivar Marta-9 merupakan kultivar baru dari perusahan benih "East West Seed" yang dipromosikan mempunyai ukuran buah yang besar (sampai $170 \mathrm{~g} /$ buah) dan merupakan field tomato yang dibudidayakan di lahan terbuka dan tahan terhadap penyakit tular tanah. Penanaman tomat kultivar ini dengan menggunakan sistem hidroponik diharapkan dapat memaksimalkan potensi hasil buah, sehingga dapat mendekati kualitas 'beef tomato'. Keuntungan lainnya tomat hibrida lokal ini relatif tahan terhadap temperatur tinggi, sehingga dapat ditanam di dataran medium seperti di Jatinangor.

Untuk menekan biaya nutrisi yang tinggi perlu dicari alternatif budidaya lain, antara lain ditanam dengan sistem budidaya non hidroponik dalam rumah plastik, yaitu penanaman dalam polybag namun menggunakan media campuran arang sekam dan kompos,sedang pemberian nutrisinya dengan pupuk buatan lengkap, alternatif lain lagi yang dapat digunakan adalah mencoba sistem semi hidroponik, yaitu menggabungkan sistem hidroponik dengan non hidroponik. Pada sistem semi hidroponik, media yang digunakan seperti pada non hidroponik, yaitu campuran arang sekam dan kompos, namun pemberian nutrisi seperti pada non hidroponik sampai tanaman mulai berbunga dan berbuah, dan pada stadia pembesaran buah diberikan nutrisi hidroponik agar buah dapat tumbuh besar.

Budidaya tomat umumnya dilakukan dengan menggunakan satu batang produksi atau single stem karena lebih mudah pemeliharaanya dan produksinya baik, cahaya matahari bisa masuk secara optimal dan menghasilkan buah sesuai potensi hasil yang dimilikinya.Sedangkan bila menggunakan dua batang produksi atau double stems akan menghasilkan jumlah buah yang lebih banyak dibandingkan single stem, namun bila nutrisi yang diberikan terbatas, ukuran buah dapat lebih kecil karena persaingan fotosintat. Keuntungan penanaman dengan double stems adalah jumlah buah yang diperoleh dalam waktu yang sama akan lebih banyak dibandingkan dengan single stem (Maboko and Plooy, 2009).

Percobaan ini dilakukan dengan menggabungkan system budidaya seperti dikemukakan di atas dan jumlah batang produksi yang dipelihara, dengan tujuan mempelajari sistem budidaya dalam rumah plastik yang dapat menghasilkan tomat kultivar Marta-9 dengan kualitas dan kuantitas baik, waktu produksi lebih singkat serta dengan nutrisi yang relatif lebih murah, sehingga biaya produksi dapat lebih rendah.

Onggo, dkk. : Pertumbuhan, hasil dan kualitas tomat cv. Marta-9 pada berbagai

sistem budidaya dalam rumah plastik di dataran medium Jatinangor 


\section{Bahan dan Metode}

Percobaan dilakukan di dalam rumah plastik Laboratorium Kultur Terkendali Fakultas Pertanian Universitas Padjadjaran, dengan ketinggian tempat $730 \mathrm{~m}$ di atas permukaan laut, dilaksanakan dari bulan Juni sampai bulan Oktober 2013.

Rancangan percobaan yang digunakan adalah Rancangan Acak Kelompok (RAK) pola faktorial yang terdiri dari dua faktor dengan empat ulangan. Faktor pertama adalah sistem budidaya yang terdiri dari tiga taraf (hidroponik, semi hidroponik dan non hidroponik) dan faktor kedua adalah jumlah batang produksi yang terdiri dari dua taraf (batang tunggal dan batang ganda). Setiap plot terdiri dari 10 tanaman. Jumlah sampel tiap plot 4 tanaman untuk pengamatan pertumbuhan dan data hasil diambil dari keseluruhan tanaman dalam plot.

Benih tomat yang digunakan adalah $\mathrm{cv}$. Marta-9 Hibrida F1. Perlakuan sistem budidaya hidroponik menggunakan media arang sekam dan nutrisi dengan formula larutan hara Jatinangor 1 dan 2. Diaplikasikan tiap hari bersamaan dengan penyiraman. Perlakuan sistem semi hidroponik menggunakan cam-puran media arang sekam dan kompos dengan perbandingan volume $3: 1$ dan menggunakan pupuk NPK 25:7:7 $8 \mathrm{~g} / \mathrm{L}$ pada awal pertumbuhan tanaman hingga 4 MST (minggu setelah tanam), kemudian diberikan NPK 16:16:16 $8 \mathrm{~g} / \mathrm{L}$ pada stadia generatif awal (4 - 6 MST), diaplikasikan 2 kali seminggu dan dilanjutkan dengan formula larutan hara Jatinangor 2 untuk pembesaran buah pada 6 MST sampai panen selesai. Perlakuan sistem non hidroponik menggunakan campuran media arang sekam dan kompos dengan perbandingan volume $1: 1$ dan menggunakan pupuk NPK 25:7:7 8 g/L pada awal pertumbuhan tanaman (hingga 4 MST) dan NPK 16:16:16 $8 \mathrm{~g} / \mathrm{L}$ pada saat generatif awal (4-6 MST) kemudian diberikan pupuk lengkap 'Grower' (N:P:K:Mg:S:B:Mn:Zn = 15:9:20:2:3,8: 0,015:0,02:0,02) untuk pembesaran buah (6 MST panen selesai). Pada penelitian ini jumlah tandan buah per tanaman yang akan diproduksi adalah 6 tandan.

Pengamatan pertumbuhan tanaman dilakukan terhadap : tinggi tanaman $(\mathrm{cm})$, jumlah daun (helai) per tanaman, diameter batang ( $\mathrm{mm}$ ), panjang dan lebar daun terbesar $(\mathrm{cm})$. Variabel hasil dan kualitas hasil yang diamati meliputi: jumlah buah (butir) per tanaman, bobot buah (g) per tanaman, persentase buah layak pasar (\% LP) dan tidak layak pasar (TLP), serta persentase buah berdasarkan kelas kualitas (A dan B). Untuk mengetahui pengaruh perla-kuan yang diberikan, digunakan uji $\mathrm{F}$ dengan taraf nyata $5 \%$, sedangkan untuk menguji perbedaan nilai ratarata perlakuan dilakukan dengan uji Duncan pada taraf nyata 5\% (Gasperz, 1995).

\section{Hasil dan Pembahasan}

Pengamatan Pertumbuhan Tanaman. Data hasil analisis statistik menunjukkan tidak terjadi interaksi antara sistem budidaya dengan jumlah batang produksi pada semua komponen pertumbuhan dan hasil yang diamati dalam penelitian ini.Data yang disajikan berikut ini merupakan pengaruh mandiri dari tiap faktor perlakuan.

Perbedaan sistem budidaya pada penelitian ini berpengaruh terhadap pertumbuhan tanaman, terutama terlihat pada pengamatan tinggi tanaman dan diameter batang umur 8 MST (Tabel 1). Pada sistem budidaya hidroponik, tanaman nyata lebih tinggi dibanding sistem semi hidroponik dan pada sistem semi hidroponik tanaman lebih tinggi dibanding pada non hidroponik. Pada pengamatan dia-meter batang, perlakuan hidroponik dan semi hidroponik menunjukkan diameter batang yang sama, namun lebih besar dibanding pada non hidroponik. Perbedaan antara ketiga sisitem hidroponik adalah pada pemberian nutrisinya, nutrisi hidroponik menggunakan formula Jatinangor 1 dan 2 yang berisi hara lengkap dengan komposisi yang biasa digunakan untuk tanaman tomat, khususnya untuk tomat 'beef' yang buahnya berukuran besar.

Nutrisi yang diberikan pada sistem non hidroponik, pada awal pertumbuhan menggunakan pupuk majemuk NPK (25:7:7), kemudian NPK (16:16:16) dan hara mikronya diharapkan dapat terpenuhi dari kompos yang diberikan dalam media tanam. Nutrisi yang diberikan pada sistem semi hidroponik pada pertumbuhan awal sama dengan non hidroponik dan pada stadia pembesaran buah digunakan nutrisi hidroponik. Nampaknya jumlah, komposisi dan interval pemberian dari ketiga cara pemupukan tersebut kurang berimbang walaupun dalam perhitungan unsur haranya sudah diperhitungkan tidak jauh berbeda, namun kelarutan pupuk dan interval

Onggo, dkk. : Pertumbuhan, hasil dan kualitas tomat cv. Marta-9 pada berbagai sistem budidaya dalam rumah plastik di dataran medium Jatinangor 
pemberiannya berbeda, pada hara hidroponik yang mudah larut diberikan tiap hari karena media arang sekam tidak dapat mengikat larutan hara dengan baik, sedang pada penggunaan pupuk majemuk diberikan dua kali seminggu dengan asumsi tersedianya kompos dapat mengikat pupuk tersebut, sehingga tidak perlu diberikan tiap hari.Perbedaan tersebut nyatanya memberikan pengaruh yang berbeda. Sistem semi hidroponik dan non hidroponik yang diaplikasikan pada penelitian ini belum dapat mengimbangi sistem hidroponik. Pengaruh pupuk pada tanaman dipengaruhi selain oleh jenis, komposisi, dosis pupuk yang digunakan, juga oleh cara aplikasi dan waktu aplikasinya.Wasonowati (2011) menyatakan bahwa ketersediaan hara yang cukup dan seimbang merupakan faktor penting yang dibutuhkan tanaman untuk menunjang laju pertumbuhan vegetatif yang baik. Pertumbuhan tinggi tanaman berkaitan dengan pertumbuhan batang, daun dan sistem perakaran tanaman. Sedang menurut Akyas, et al. (2004) diameter batang merupakan variabel pengamatan yang menunjukkan kekuatan tumbuh tanaman tomat karena merupakan pusat titik tumbuh tanaman.

Hasil pengamatan pada ukuran daun umur 6 MST (Tabel 2.) lebih jelas menunjukkan perbedaan tersebut. Sampai umur 6 MST perlakuan dengan sistem semi hidroponik dan non hidroponik pemberian haranya sama, yaitu diberikan dari pupuk majemuk, sehingga ukuran daun yang dihasilkan sama, namun keduanyalebih kecil dibanding dengan pada sistem hidroponik. Penelitian Balia et al. (2012) menunjukkan bahwa ketersediaan unsur hara bagi tanaman akan mempengaruhi kecepatan pertumbuhan dan perkem-bangan daun, batang dan akar tanaman tersebut. Besarnya jumlah dan komposisi nutrisi yang diberikan akan berpengaruh pada pertumbuhan tanaman.

Perlakuan jumlah batang produksi berpengaruh pada tinggi tanaman, jumlah daun dan ukuran daun (Tabel 1 dan 2). Pada batang ganda tanaman lebih pendek, karena fotosintat yang dihasilkan tidak hanya digunakan untuk pertumbuhan tinggi tanaman, juga untuk pertumbuhan cabang, namun dari masing-masing batang ada pertumbuhan daun, sehingga jumlah daun lebih banyak dan konsekwensinya ukuran daun lebih kecil. Hasil pengamatan ini menunjukkan bahwa jumlah hara yang diberikan tidak berlebih, sehingga pada perlakuan batang ganda sudah terlihat adanya kompetisi antar organ dalam tanaman.
Tabel 1. Pengaruh Sistem Budidaya dan Jumlah Batang Produksi terhadap Tinggi Tanaman dan Diameter Batang, Umur 8 MST.

\begin{tabular}{lll}
\hline \hline Perlakuan & $\begin{array}{l}\text { Tinggi } \\
\text { tanaman }(\mathbf{c m})\end{array}$ & $\begin{array}{l}\text { Diameter } \\
\text { batang }(\mathbf{c m})\end{array}$ \\
\hline Sistem budidaya & & \\
Hidroponik & $179.4 \mathrm{a}$ & $13.89 \mathrm{a}$ \\
Semi hidroponik & $171.2 \mathrm{~b}$ & $13.66 \mathrm{a}$ \\
Non hidroponik & $163.2 \mathrm{c}$ & $13.41 \mathrm{~b}$ \\
\hline Jumlah batang & & \\
produksi & & \\
Batang tunggal & $174.0 \mathrm{a}$ & $13.62 \mathrm{a}$ \\
Batang ganda & $168.6 \mathrm{~b}$ & $13.68 \mathrm{a}$ \\
\hline \hline
\end{tabular}

Keterangan : Nilai rata-rata yang diikuti huruf yang sama pada masing-masing kolom, menunjukkan tidak berbeda nyata menurut uji Duncan taraf 5\%.

Tabel 2. Pengaruh Sistem Budidaya dan Jumlah Batang Produksi terhadap Jumlah Daun dan Ukuran Daun Terbesar, Umur 6 MST.

\begin{tabular}{lccc}
\hline \hline Perlakuan & $\begin{array}{c}\text { Jumlah } \\
\text { daun }\end{array}$ & \multicolumn{2}{c}{ Ukuran daun terbesar } \\
\cline { 3 - 4 } & \multicolumn{4}{c}{ Panjang(cm) } & Lebar $(\mathbf{c m})$ \\
\hline Sistem budidaya & & & \\
Hidroponik & $14.2 \mathrm{a}$ & $57.8 \mathrm{a}$ & $38.1 \mathrm{a}$ \\
Semi hidroponik & $14.1 \mathrm{a}$ & $52.1 \mathrm{~b}$ & $34.4 \mathrm{~b}$ \\
Non hidroponik & $13.5 \mathrm{a}$ & $54.1 \mathrm{~b}$ & $36.2 \mathrm{~b}$ \\
\hline Jumlah batang & & & \\
produksi & & & \\
Batang tunggal & $12.1 \mathrm{a}$ & $55.8 \mathrm{a}$ & $37.6 \mathrm{a}$ \\
Batang ganda & $15.7 \mathrm{~b}$ & $53.5 \mathrm{~b}$ & $34.9 \mathrm{~b}$ \\
\hline \hline
\end{tabular}

Pengamatan Hasil dan Kualitas Hasil. Pengamatan pada hasil buah menunjukkan bahwa jumlah buah/tanaman, dan bobot buah/tanaman pada sistem hidroponik nyata lebih tinggi dibanding pada sistem semi hidroponik dan pada perlakuan semi hidroponik lebih tinggi dibanding pada sistem non hidroponik (Tabel 3) Perbedaan jumlah buah tersebut terutamadisebabkan terjadi busuk ujung buah atau blossom end rot (BER) yang cukup tinggi (18\%) pada perlakuan non hidroponik dan pada perlakuan semi hidroponik (14\%), sedang pada sistem hidroponik sangat rendah, yaitu $2 \%$. Penyebab BER pada dasarnya karena kekurangan kalsium pada tanaman tomat dan terjadi karena adanya fluktuasi pasokan air pada tanaman (pada sistem non hidroponik penyiraman dilakukan 1 hari 1 kali, pada sisitem hidroponik 2-3 kali sehari). Pada kondisi suhu udara yang tinggi dengan pemberian air yang berlebihan akan menyebabkan evapotranspirasi tanaman yang

Onggo, dkk. : Pertumbuhan, hasil dan kualitas tomat cv. Marta-9 pada berbagai

sistem budidaya dalam rumah plastik di dataran medium Jatinangor 
tinggi, sehingga kalsium (Ca) sebagai bahan pembentuk kulit buah tidak dapat diserap tanaman, akibatnya ujung buah tidak tahan penguapan tinggi sehingga mengkerut kemudian berwarna coklat (Kemble et al., 2013). Buah yang terkena BER segera dipetik dan dibuang agar hara tanaman dapat dialihkan pada pembesaran buah yang lain, namun jumlah buah yang dapat dipanen menjadi lebih sedikit. Alasan lain adalah bahwa kalsium dibutuhkan oleh tanaman dalam jumlah yang tidak banyak, pemberian kompos dalam media biasanya sudah dapat mencukupi kebutuhan akan hara ini, namun diduga tanaman tomat cv. Marta-9 peka terhadap BER, sehingga gejala tersebut timbul dan mempengaruhi hasil. Tersedianya Ca dalam larutan hidroponik nyata menekan timbulnya gejala BER, namun pemberiannya pada stadia generatif saja seperti pada kasus semi hidroponik, gejala BER masih terjadi, hanya intensitasnya lebih rendah. Data hasil pada bobot buah per tanaman sejalan dengan jumlah buahnya,pada sistem hidroponik bobot buah / tanaman lebih tinggi dibanding sistem semi hidroponik dan pada non hidroponik lebih rendah dibanding semi hidroponik.

Tabel 3. Pengaruh Sistem Budidaya dan Jumlah Batang Produksi terhadap Jumlah Buah/Tanaman dan Bobot Buah/Tanaman.

\begin{tabular}{|c|c|c|}
\hline Perlakuan & $\begin{array}{c}\text { Jumlah } \\
\text { buah/tanaman }\end{array}$ & $\begin{array}{l}\text { Bobot buah/ } \\
\text { tanaman }(\mathrm{g})\end{array}$ \\
\hline \multicolumn{3}{|l|}{ Sistem budidaya } \\
\hline Hidroponik & $27.9 \mathrm{a}$ & $2326.7 \mathrm{a}$ \\
\hline Semi hidroponik & $26.5 \mathrm{~b}$ & $2059.6 \mathrm{~b}$ \\
\hline Non hidroponik & $23.3 \mathrm{c}$ & $1741.8 \mathrm{c}$ \\
\hline \multicolumn{3}{|l|}{$\begin{array}{l}\text { Jumlah batang } \\
\text { produksi }\end{array}$} \\
\hline Batang tunggal & $24.5 \mathrm{a}$ & 1972.9 a \\
\hline Batang ganda & $27.2 \mathrm{~b}$ & $2112.5 \mathrm{a}$ \\
\hline
\end{tabular}

Perlakuan batang ganda menghasilkan jumlah buah yang lebih banyak namun bobot buah per tanaman sama. Batang produksi yang produktif akan menghasilkan bunga yang memiliki peluang untuk menjadi buah apabila hara atau nutrisi yang dibutuhkan tanaman tomat tercukupi untuk peningkatan produksi tersebut (Surtinah, 2007). Bobot buah/tanaman yang dihasilkan erat hubungannya dengan pertumbuhan vegetatif tanaman, antara lain dari jumlah dan ukuran daun. Pada perlakuan batang ganda jumlah daun lebih banyak namun ukurannya lebih kecil dibanding perlakuan batang tunggal, sehingga bobot buah yang dihasilkan tidak berbeda. Penggunaan batang ganda pada tanaman tomat mempunyai kelebihan yaitu dalam kurun waktu yang sama dapat menghasilkan buah tomat yang lebih banyak dibanding pada batang tunggal, karena pertumbuhan buah dari kedua batang berjalan bersamaan (Maboko at al., 2011).

Hasil sortasi buah menunjukkan persentase jumlah buah tidak layak pasar lebih tinggi pada budidaya sistem non hidroponik (Tabel 4.) ini disebabkan oleh banyaknya ukuran buah yang tidak memenuhi kriteria layak pasar, yaitu kurang dari 50 g. Pertumbuhan tanaman pada perlakuan ini lebih kecil, dicirikan dari diameter batang dan ukuran daun yang lebih kecil dari kedua sistem budidaya yang lain, sehingga fotosintat yang dihasilkan juga lebih sedikit. Kondisi tersebut berdampak pada ukuran buah yang lebih kecil, sehingga persentase bobot buah layak pasar juga lebih kecil dibanding sistem hidroponik dan semi hidroponik. Perlakuan jumlah batang produksi tidak berpengaruh pada persentase jumlah dan bobot buah layak pasar.

Tabel 4. Pengaruh Sistem Budidaya dan Jumlah Batang Produksi terhadap Persentase Jumlah dan Bobot Buah Layak Panen (LP) dan Tidak Layak Panen (TLP).

\begin{tabular}{lllllll}
\hline \hline Perlakuan & \multicolumn{3}{c}{ Jumlah buah } & \multicolumn{3}{c}{ Bobot buah } \\
\cline { 2 - 6 } & LP (\%) & TLP(\%) & LP (\%) & TLP(\%) \\
\hline Sistem budidaya & & & & & & \\
Hidroponik & $75.4 \mathrm{a}$ & $24.6 \mathrm{a}$ & $75.5 \mathrm{a}$ & $24.5 \mathrm{a}$ \\
Semi hidroponik & $72.2 \mathrm{a}$ & $27.8 \mathrm{a}$ & $74.8 \mathrm{a}$ & $25.2 \mathrm{a}$ \\
Non hidroponik & $65.1 \mathrm{~b}$ & $34.9 \mathrm{~b}$ & $70.8 \mathrm{~b}$ & $29.2 \mathrm{~b}$ \\
\hline Jumlah batang & & & & & & \\
produksi & & & & & & \\
Batang tunggal & $69.2 \mathrm{a}$ & $30.8 \mathrm{a}$ & $72.2 \mathrm{a}$ & $27.8 \mathrm{a}$ \\
Batang ganda & $72.6 \mathrm{a}$ & $27.4 \mathrm{a}$ & $75.2 \mathrm{a}$ & $24.8 \mathrm{a}$ \\
\hline \hline
\end{tabular}

Keterangan : Nilai rata-rata yang diikuti huruf yang sama pada masing-masing kolom, menunjukkan tidak berbeda nyata menurut Duncan's taraf 5\%.

Pada pengamatan kualitas buah, sistem budidaya hidroponik menghasilkan persentase jumlah buah kualitas A yang sama, namun bobot buah kualitas A lebih tinggi dibanding sistem semi hidroponik dan non hidroponik. Pada penelitian ini usaha untuk mendapatkan sistem budidaya alternatif yang dapat digunakan pada penanaman dalam rumah plastik ternyata belum dapat mengimbangi hasil dan kualitas buah tomat yang ditanam dengan sistem hidroponik. Peran unsur hara baik

Onggo, dkk. : Pertumbuhan, hasil dan kualitas tomat cv. Marta-9 pada berbagai sistem budidaya dalam rumah plastik di dataran medium Jatinangor 
ketersediaannya dan kemudahan diserapnya akan berpengaruh pada metabolisme tanaman dan menunjang proses fotosistesis dalam menghasilkan fotosintat untuk pengisian buah. Kelengkapan unsur hara nyata berpengaruh pada fase reproduktif untuk peningkatan kualitas buah. Perlakuan jumlah batang produk-si dalam penelitian ini juga tidak berpengaruh pada kualitas buah.

Tabel 5. Pengaruh Sistem Budidaya dan Jumlah Batang Produksi terhadap Persentase Jumlah dan Bobot Buah Kualitas A Dan B.

\begin{tabular}{|c|c|c|c|c|}
\hline \multirow[t]{2}{*}{ Perlakuan } & \multicolumn{2}{|c|}{ Jumlah buah } & \multicolumn{2}{|c|}{ Bobot buah } \\
\hline & $\mathrm{A}(\%)$ & B (\%) & A (\%) & B (\%) \\
\hline \multicolumn{5}{|c|}{ Sistem budidaya } \\
\hline Hidroponik & $34.6 \mathrm{a}$ & $65.4 \mathrm{a}$ & $39.4 \mathrm{a}$ & $60.6 \mathrm{~b}$ \\
\hline Semi hidroponik & $31.1 \mathrm{a}$ & $68.9 \mathrm{a}$ & $33.6 \mathrm{~b}$ & $66.4 \mathrm{a}$ \\
\hline Non hidroponik & $28.3 \mathrm{a}$ & $71.7 \mathrm{a}$ & $28.7 \mathrm{~b}$ & $71.3 \mathrm{a}$ \\
\hline \multicolumn{5}{|l|}{$\begin{array}{l}\text { Jumlah batang } \\
\text { produksi }\end{array}$} \\
\hline Batang tunggal & $30.8 \mathrm{a}$ & $69.2 \mathrm{a}$ & $34.9 \mathrm{a}$ & $65.1 \mathrm{a}$ \\
\hline Batang ganda & $30.4 \mathrm{a}$ & $69.6 \mathrm{a}$ & $33.3 \mathrm{a}$ & $66.7 \mathrm{a}$ \\
\hline
\end{tabular}

\section{Kesimpulan dan Saran}

Tidak terdapat hubungan yang saling mempengaruhi antara pengaruh jumlah batang produksi dengan sistem budidaya terhadap semua parameter yang diamati pada tanaman tomat $\mathrm{cv}$. Marta-9 yang ditanam di dalam rumah plastik di Jatinangor.

Sistem budidaya semi hidroponik dan non hidroponik pada penanaman tomat cv. Marta-9 yang dilakukan dalam penelitian ini menghasilkan pertumbuhan tanaman yang lebih rendah dicirikan dengan tinggi tanaman dan diameter batang serta ukuran daun yang lebih rendah dibanding sistem budidaya hidroponik. Tingginya jumlah buah yang terkena blossom end rotpada sistem budidaya semi dan non hidroponik berimbas pada jumlah buah dan bobot buah per tanaman yang lebih rendah, serta persentase bobot buah kualitas A yang lebih rendah dibandingkan sistem budidaya hidroponik.

Perlakuan batang tunggal menghasilkan tanaman dengan tinggi tanaman dan ukuran daun yang lebih besar dibanding penggunaan batang produksi ganda, namun baik perlakuan batang tunggal atau ganda menghasilkan persentase jumlah dan bobot buah layak pasar serta persentase bobot dan jumlah buah kualitas A yang sama.

\section{Ucapan Terima Kasih}

Ucapan terima kasih saya berikan kepada Ibu Anne Nuraini, Esa Nurul Hidayat dan semua pihak yang terlibat.

\section{Daftar Pustaka}

Akyas, A. M., D. Widayat, Nursuhud (2004). Research and development in hydroponics technology at the Laboratory of Horticul-ture Padjadjaran University (a case with tomato cultivar Recento). The 5th Int'1 SymposiumCum-Workshop in Southeast Asia. The Role of German Alumni In Rural/ Regional Development And Entre-preneurship, 2327 August 2004, Phnom Penh - Cambodia.

Balia, P., Tripatmasari, M. dan Wasonowati, C. 2012. Pengaruh media tanam dan nutrisi terhadap pertumbuhan dan hasil tanaman pakchoi (Brassica juncea L.) dengan sistem hidroponik. Agrovigor vol. 5 No. 1.

Kanyomeka, L., and Shivute, B., 2005. Influence of pruning on tomato production under controlled environments. Agricultura Tropica et Subtropica. Vol..38(2).

Kemble, J., E. Sikora, and M.B. Musgrove. 2013. Blossom-End Rot In Tomatoes: Causes and Prevention. Alabama Cooperative Extension System ANR -1059. Online pada : http://www.aces.edu/pubs/docs/A/AN R-1059/ANR-1059.pdf

Maboko, M. M and C. P. Du Plooy. 2009. Effect of stem and fruit prunning on yield and quality of hidroponically grown tomato. Afric Crop. Sci. Conf. Proc. Vol. 9: p.27-29.

Surtinah. 2007. Kajian tentang hubungan pertumbuhan vegetatif dengan produksi tanaman tomat (Lycopersicum esculentum Mill). Jurnal Ilmiah Pertanian Vol. 4 No. 1

Wasonowati, C. 2011. Meningkatkan pertumbuhan tanaman tomat (Lycopersicon esculentum) dengan sistem budidaya hidroponik. Agrovigor Vol. 4 No.1.

Onggo, dkk. : Pertumbuhan, hasil dan kualitas tomat cv. Marta-9 pada berbagai

sistem budidaya dalam rumah plastik di dataran medium Jatinangor 